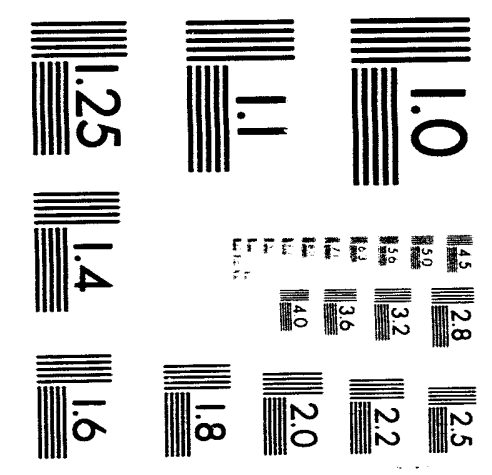



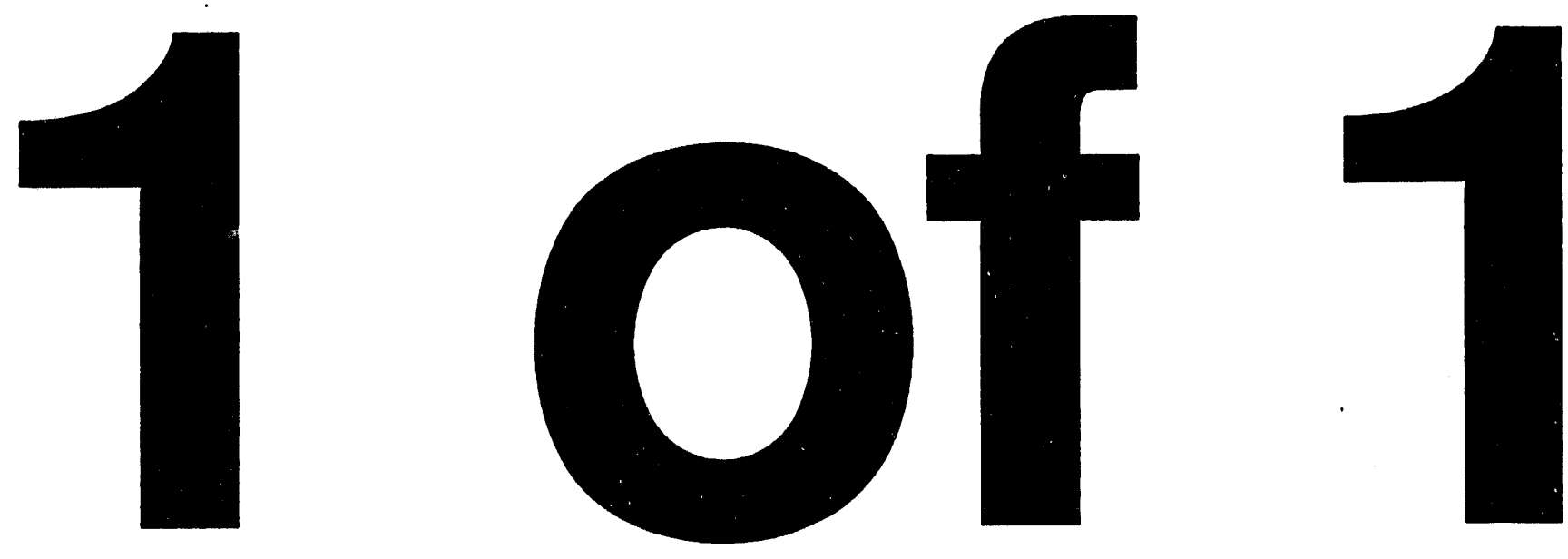


\title{
High-Speed Repetitive Pellet Injector for Plasma Fueling of Magnetic Confinement Fusion Devices*
}

\author{
S. K. Combs, L. R. Baylor, C. R. Foust, M. J. Gouge, and S. L. Milora \\ Oak Ridge National Laboratory, Oak Ridge, Tennessee, 37831-8071, USA
A. Frattolillo, M. Gasparotto, S. Migliori, F. Scaramuzzi, G. Angelone, M. Baldarelli, M. Capobianchi, C. Domma, and G. Ronci
ENEA, Centro Ricerche Energia Frascati, Frascati, Rome, Italy

\begin{abstract}
The projected fueling requirements of future magnetle confinement devices for controlled thermonuclear research [e.gon the International Thermonuclear Experimental Renctor (ITER)] Indlcate that a fexible plasema fueling capability is required. This Includes a mix of traditlonal gas puming and low- and highvelocity deuterium-tritlum pellets. Conventional pellet injectors (based on Ught gas guns or centrifugal accelerators) can rellably provide frozen hydrogen pellets (1- to 6-mm-diam sizes tested) up to $-1.3-\mathrm{km} / \mathrm{s}$ velocity at the appropriate pellet fuellng rates (1 to $10 \mathrm{~Hz}$ or greater). For long-pulee operation in a higher velocity regime $(>2 \mathrm{~km} / \mathrm{s})$, an experiment in collaboration between Oak Ridge Natlonal Laboratory (ORNL) and ENEA Frascati is under way. Thls activity will be carried out in the framework of a collaborative agreement between the U.S. Department of Energy and European Atomic Energy Community - ENEA Association. In this experiment, an existing ORNL hydrogen extruder (equipped with a pellet chambering mechanism/gun barrel ascembly) and a Frascatl two-stage light gas gun driver have been comblned on a teat facility at ORNL. Initial testing has been carried out with alngle deuterium pellets accelerated up to $2.05 \mathrm{~km} / \mathrm{s}$ with the two-stage driver; in addition, some preliminary repetitive teating (to commisalon the diagnostics) was performed at reduced speeds, Including sequences at 0.5 to $1 \mathrm{~Hz}$ and 10 to 30 pellets. The primary objective of this atudy $\mathrm{s}$ to demonotrate repetitive operation (up to $-1 \mathrm{~Hz}$ ) with speeds in the $2-10 \mathrm{3}-\mathrm{km} / \mathrm{s}$ range. In additlon, the strength of extruded hydrogen ice as opposed to that produced in situ by direct condensation in pipe guns can be investigated. The equipment and Initial experimental results are described.
\end{abstract}

\section{INTRODUCTION}

The process and benefits of plasma fueling by pellet injection have been demonstrated conclusively on a number of toroidal magnetic confinement configurations; consequently, pellet injection is the leading technology for deep fueling of magnetically confined plasmas for controlled thermonuclear fusion research $[1,2]$. ITER and future fusion reactors will require a flexible plasma fueling capability to satisfy the multiple physics and engineering constraints of fusion power density, burn control, tritium burn fraction, edge density for plasma mode $(\mathrm{L}, \mathrm{H})$ control, and gaseous divertor density for efficient plasma exhaust and protection of plasma-facing components [3]. Pellet fueling offers a unique capability for influencing the performance of ITER core plasmas: large, high-speed pellets injected during the burn phase may provide sufficient control of the density profile to allow operation in a region of enhanced thermal reactivity, and high-speed pellets

\footnotetext{
"Research sponsored by the Office of Fusion Energy, U.S Department of Energy, under contract DE-AC05-84OR21400 with Martin Marietta Energy Systems, Inc.

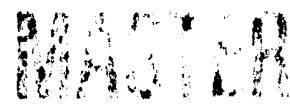

injected in the start-up phase could provide improved ignition margins. Deeper fueling capability allows isotopic tailoring of the various fueling sources and more control of the tritium burn fraction and global tritium inventory.

With the reliable operation of conventional injectors in the $0.5-$ to $1.5-\mathrm{km} / \mathrm{s}$ velocity range demonstrated on many experiments, some researchers have recently concentrated on increasing the pellet velocity. Faster pellets can penetrate more deeply into large, hot plasmas and deposit atoms of fuel directly into a larger fraction of the plasma volume. Many advanced acceleration concepts have been considered, with experimental studies reported on (1) the two-stage light gas gun, (2) the electrothermal accelerator, (3) the electromagnetic rail gun, and (4) the electron-beam-heated rocket. Summaries of these specific research efforts, as well as a recent review of pellet injector technology can be found in [4]. Of the advanced acceleration concepts, the two-stage light gas gun technique is the most mature technology, with pellet speeds of $\sim 3 \mathrm{~km} / \mathrm{s}$ achieved routinely in laboratory experiments using single-shot devices and bare deuterium pellets. Two-stage guns (single-shot devices) have recently been installed on the tokamak experiments FTU $[5,6]$, Tore Supra [7], and TFTR [8,9] and used to inject single pellets into plasmas at speeds of 2.0 to $2.5 \mathrm{~km} / \mathrm{s}$. A small ORNL twostage light gas gun [10] previously demonstrated repetitive operation at $1 \mathrm{~Hz}$ and $3 \mathrm{~km} / \mathrm{s}$ with plastic surrogate pellets, and similar parameters with cryogenic pellets are a goal of the present study.

All of the two-stage research reported to date with bydrogen pellets has used the pipe gun technique and thus is limited to a single pellet per barrel. In the present study, hardware from ORNL and ENEA Frascati have been combined: (i) the ORNL cryogenic hydrogen extruder [11,12] (equipped with a pellet chambering mechanism/gun barrel assembly), which has been used for long-pulse fueling experiments on several major fusion devices (DIII, TFIR, and JET) and can provide up to $\sim 100$ small pellets $(2.7 \mathrm{~mm})$ in a single extrusion sequence and (ii) the Frascati repeating twostage light gas gun (RTSG), which has been used to reliably accelerate single deuterium pellets to velocities as high as $3.3 \mathrm{~km} / \mathrm{s}$ in the laboratory $[6,13]$. The primary objective of this work is to experimentally evaluate the capabilities of these combined technologies. The new long-pulse injector has the potential to provide pellets at velocities approximately twice that available from present long-pulse pellet injection systems, which has been limited to $\sim 0.5$ to $1.3 \mathrm{~km} / \mathrm{s}$ with deuterium pellets.

The CNPM group paper [14] at this meeting also describes work carried out as part of this collaboration. This group is experimentally addressing the issue of piston design and wear, which is of great importance for repetitive two-stage injectors.
OISTRIBUTION OF THIS DOCUMENT IS UALIMITER 


\section{ORNL EXTRUDER AND GUN ASSEMBLY}

Most of the hardware from the original ORNL repeating pneumatic pellet injector [12], previously used for repetitive fueling on the Tokamak Fusion Test Reactor (TFIR) [15], is used in the present experimental study. A schematic of the cryogenic hydrogen extruder is shown in Fig. 1, including a photograph of the clear deuterium ice filament at $14 \mathrm{~K}$. The extruder apparatus serves both to solidify (or freeze) hydrogen isotopes and to force feed the resulting solid to the acceleration section. The operation of ORNL extruders has been described in detail previously $[11,12,15]$. Also, the pellet chambering mechanism/gun barrel assembly from the original hardware is being used; however, the rear plate of the vacuum housing vessel was modified to accommodate the Frascati two-stage gun (Fig. 2). With the new configuration, the original propellant valve and Frascati two-stage apparatus are interchangeable with minimal effort. The bottom cold block that accommodates the acceleration device and the chambering mechanism/barrel combination unit is maintained at solid hydrogen temperatures (10 to $16 \mathrm{~K}$ for deuterium). The pellet diameter is established by the inside diameter of the stainless steel tubing used for the gun barrel, which is presently $2.7 \mathrm{~mm}$. The gun assembly uses a punch-type chambering mechanism in which the gun barrel is brazed directly to a solenoid plunger. When the solenoid is activated, the knife-edge end of the barrel is driven into the extrusion, punching out and chambering a pellet. While the punch mechanism is engaged (solenoid energized), the propellant (hydrogen or belium) is admitted to the gun breech via the acceleration device. With the propellant valve installed, the system has been tested at $1 \mathrm{~Hz}$ and $\sim 1.0 \mathrm{~km} / \mathrm{s}$ with deuterium pellets, including sequences with up to 100 pellets from a single extruder charge of deuterium. The pellet size can be changed with some mechanical modifications (barrel and gun assembly mechanisms).

An alternative chambering technique was employed on the three-barrel repeating pneumatic pellet injector used for plasma fueling experiments on the Joint European Torus $[16,17]$; for that application a separate tube on the breech side of the gun punched out and chambered the pellets. This arrangement is an option for this experimental study.

\section{ENEA FRASCATI REPEATING TWO-STAGE GUN}

A schematic of the Frascati RTSG is shown in Fig. 3, and the design parameters of the device are listed in Table I. The design and operation of the Frascati guns, including the diagnostics and control systems, have been given elsewhere $[5,6,13,18]$. With the Frascati RSTG controls, the repetition rate may be changed "on-line" (i.e., while the RTSG is running) from single-shot operation up to $1 \mathrm{~Hz}$ by simply modifying the content of a hold register in the Programmable Logic Controller (Allen Bradley SLC500). Also, it is possible to vary the pellet velocity on-line by adjusting the set point of the initial gas filling pressure of the pump tube while the firststage reservoir pressure is held constant. The RTSG was tested extensively in Frascati, demonstrating reliable and reproducible performance. More than 8000 shots were made using hydrogen gas in both stages of the gun, including up to 1600 consecutive shots at a $1-\mathrm{Hz}$ rate and pressure pulses of about 700 bar, without observing significant degradation in performance. These shots were made without a projectile or gun barrel, which can be accomplished either by closing the downstream valve or installing a solid blank flange. Toward the end of this experimental run, the amplitude of the pressure pulses produced by the RSTG was only about $10 \%$ lower (on the average) than at the beginning; also, it was possible to recover the initial performance by slightly changing on-line the pump tube filling pressure. The piston (whose initial diameter was $24.98 \mathrm{~mm}$ ) was then extracted from the pump tube to check its condition. It turned out to have a slight conical shape with a decreasing diameter from the rear $(24.85 \mathrm{~mm})$ to the front $(24.75 \mathrm{~mm})$ and a rather scratched lateral surface.

Table I

Main parameters of the ORNL/Frascati injector

\begin{tabular}{ll}
\hline \multicolumn{1}{c}{ Frascati two-stage gun } \\
First suge reservoir volume $\left(\mathrm{cm}^{3}\right)$ & 325 \\
Pump tube ID (mm) & 25.03 \\
Pump tube length (mm) & 350 \\
Piston material per gal & Al alloy (ergal) \\
Piston mass (g) & -10 \\
Piston length (mm) & -14 \\
Piston diameter (mm) & 24.97 \\
Operating gases & $\mathrm{H}_{2}$ or He \\
& ORNL extruder/gun assembly \\
Pellet muterial & $\mathrm{D}_{2}$ \\
Barrel length (mm) & 800 \\
Barrel ID (mm) & 2.7 \\
Pellet nominal length (mm) & $2.7(\times 2$ and 3$)$ \\
pellet nominal mass (mg) & $3(\times 2$ and 3$)$ \\
\hline
\end{tabular}

\section{INTEGRATED ORNL/FRASCATI TEST FACILITY}

The Frascati RTSG was recently installed on the repeating pneumatic injector (RPI) test facility at ORNL. A schematic of the integrated test facility is shown in Fig. 4. The experiment is equipped with instrumentation for tracking fast transients during gun firings. Diagnostics in the vacuum injection line provide velocity, relative mass, and photographic information to thoroughly document each pellet shot. A light barrier (at the gun muzzle) and a mass microwave detector [19] (1.2 m downstream of gun muzzle) through which pellets pass supply timing data for accurately evaluating pellet speeds (each is also equipped with flash lamps and cameras for photography). At the end of the injection line, a target plate intercepts the pellets and indicates pellet dispersion and integrity; this target also provides timing data for redundant velocity measurements, since it is equipped with a shock accelerometer.

The MicroVAX-based CAMAC data acquisition system is gated to provide maximum data for each individual pellet. The data window size is totally dependent on the individual digitizer frequency and the number of pellets to be fired. Typically, up to six channels of transient data for each pellet are recorded and archived with three CAMAC digitizers (two signals per digitizer) sampling at individual frequencies of up to $1 \mathrm{MHz}$, corresponding to a $1-\mu \mathrm{s}$ resolution. Pellet photography in the microwave cavity is accomplished by using a CID camera and frame grabber to digitize video images of pellets back lit by a diffuse 3-ns laser flash. The frame grabber is hosted by a personal computer and can capture up to thirty-two $512 \times 512$ pixel video images before 
being off-loaded to the computers hard disk. Once stored on the computer, the pellet images can be manipulated and enhanced by image processing software.

\section{INTTLAL TEST RESULTS AND FUTURE PLANS}

Initial experiments have recently been carried out in the test facility at ORNL. Hundreds of deuterium pellets have been formed and accelerated with the RTSG operating with helium or hydrogen gas, including several sequences in which 10 to 30 pellets were fired at a frequency of 0.5 to $1 \mathrm{~Hz}$ (pellet velocities $<1 \mathrm{~km} / \mathrm{s}$ ). The frequency was actively changed during some of the test sequences, as discussed previously. However, for the most part, the early experiments have concentrated on single shots for commissioning of components and diagnostics and the optimization of operating parameters. The highest recorded pellet velocities have been in the range of 1.70 to $2.05 \mathrm{~km} / \mathrm{s}$. For two test shots (9212 and 9138), pellet photographs are shown in Fig. 5 along with the measured downstream pump tube pressure pulse. In the course of some exploratory experiments, it was discovered that multiple chambering of the punch mechanism, while extruding and before firing of the gun, was an effective technique to produce larger pellets. For example, the pellet in Fig. 5(b) is the result of two sequential chambering actions, and the pellet size is about twice that of the standard pellet in Fig. 5(a). Even longer pellets were observed after three chambering actions. With this type of injector, this technique adds even greater flexibility (variable mass) for plasma fueling experiments.

The initial experimental results have been encouraging. Future tests will concentrate on pushing the pellet velocity as high as possible and exploring the repetitive operating regime, with an objective of reliable repetitive operation at $\sim 1 \mathrm{~Hz}$ and pellet velocities in the range of 2 to $3 \mathrm{~km} / \mathrm{s}$. Several codes are available to model the performance of two-stage guns, including two (ii and iii) especially adapted for the acceleration of hydrogen ice: (i) a 1-D Lagrangian code[20], (ii) a 0-D/1-D PC-based QUICKGUN code [21], and (iii) a O-D/1-D TRUCCO code developed in Italy [22] and run on a UNIX workstation. These codes are useful both in optimizing gun design and performance and in providing a better understanding of the physics of two-stage guns in general and have been used extensively in this study.

\section{REFERENCES}

[1] S. L. Milora. "Review of pellet fueling," J. Fusion Energy, Vol. 1, p. 15, 1981 .

[2] S. L. Milora, "Review of hydrogen pellet injection technology for plasma fueling," J. Vac. Sci. Technol. Vol. A 7, p. $925,1989$.

[3] W. A. Houlberg, S. E. Attenberger, and M. J. Grapperhaus, "Density profile contol in a fusion resctor using pellet injection," unpublished.

[4] S. K. Combs "Pellet injection technology," Rev Sci. Instrum. Vol. 64 No. 8, p. 1679, 1993.

[5] L. Martinis et al., "A new two-stage pellet injector for FTU," in Proceedings of the 13th IEEE Symposium on Fusion Engineering, Knarville, 1989 Vol. 2, New York: IEEE 1990, p. 1248.

[6] A. Frattolillo et al., "High-speed pellet injectors for the Frascati Tokamak Upgrade," in Fusion Technology 1992 (Proc. 17th Symposium, Rome, Italy, September 14-18, 1992), Eds. C. Ferro, M. Gasparotto, and H. Knoepfel, Vol. I, North-Holland: Elsevier Science Publishers B. V., 1993, pp. 505-509. (Also F. Alladio, "MHD and Confinement During Pellet Injection in FTU," Presented at the 20,h EPS Conference on Controlled Fusion and Plasma Physics. Lisboe, Portugal, July 26-30, 1993, in press).

[7] J. P. Perin, G. Claudet, F. Disdier, J. Lefferranderie, A. Géraud, and G. Gros, "Tore Supra High Speed Pellet Injector," in Fusion Technology 1992 (Proc. 17th Symposium, Rome, Italy, September 14-18, 1992), Eds. C. Ferro, M. Gasparotto, and H. Knoepfel, Vol. I, North-Holland: Elsovier Science Publishers B. V., 1993, pp.613-617. (also J. P. Perin, G. Claudet, F. Disdier, J. Lafferranderie, A. Géraud, and G. Gros. "Tore Supra high speed pellet injector and improvements for speed up $103400 \mathrm{~ms}^{-1}$ " presented at the Workshop on Pellet Injectors. Frascati, Italy, September 21-22, 1992 (unpublished)).

[8] S. L. Milora et al. "Design of a tritium pellet injectar for TFTR," in Proceedings of the 14th Symposium on Fusion Engineering, San Diega, 1991 New York, IEEE: 1992, Vol. 2, p. 716.

[9] M. J. Gouge et al., "Tritium pellet injector for TFTR," Fusion Technol. Vol. 21, p. 1665, 1992.

[10] S. K. Combe, C. R. Foust, D. T. Fehling, M. G. Gouge, and S. L. Milora, "Repetitive two-stage light gas gun for high-speed pellet injection." Rev. Sci. Instrum. Vol. 62, p. 1978, 1991.

[11] C. A. Foster, "Solid deuterium centrifuge pellet injector," J. Vac. Sci. Technol. Vol. A 1, p. 952, 1983.

[12] S. K. Combs, S. L. Milora, C. R. Foust, C. A. Foster, and D. D. Schuresko, "Repenting pneumatic pellet injector for plasma fueling," Rev. Sci. Instrum. Vol. 56, p. 1173, 1985.

[13] E[A]. Frattolillo et al., " $3.3 \mathrm{~km} / \mathrm{s}$ solid $D_{2}$ single pellet injector for the Frascati Tokamak Upgrade," in Proceedings of the 14th Symposium on Fusion Engineering, San Diego, 1991. Vol. 2, New York: IEEE 1992. p. 721.

[14] A. Reggiori, R. Carlevaro, G. Riva, and G. Daminelli, "Experiments with the CNPM gas gun for minimizing pistons wear and propellant gas flow." Proceedings of 15th IEEENPSS Symposium of Fusion Engineering, Hyannis, Massachusetts, Oct. 11-15, 1993.

[15] S. K. Comba, S. L. Milora, C. R. Foust, G. L. Schmidt, and T. P. McBride, "Operation of a repeating pneumatic hydrogen pellet injector on the Tokamak Fusion Test Reactor," J. Vac. Sci. Technol. Vol. A 4, p. 1113, 1986.

[16] S. K. Combe, S. L. Milora, L. R. Baylor, C. R. Foust, F. E. Gethers and D. O. Sparks, "A three-barrel repeating pneumatic pellet injector for plasma fueling of the Joint European Torus," J. Vac. Sci. Technol. Vol. A 6, p. 1901, 1988.

[17] S. K. Combs et al., "Performance of a pneumatic hydrogea-pellet injection system on the Joint European Torus," Rev. Sci. Instrum. Vol. 60, p. 2697, 1989.

[18] A. Frattolillo et al., "High-Speed Repetitive Pellet Injector Prototype for Magaetic Conefinement Fusion Devices," in Fussion Technology 1992 (Proc. 17th Symposium, Rome, Italy, September 14-18, 1992), Eds C. Ferro, M. Gasparoto, and H. Knoepfel, Vol. I, North-Holland: Elsevier Science Publishers B. V., 1993, pp. 500-504.

[19] M. J. Gouge, S. K. Combs, and S. L. Milora, "A combined microwave cavity and photographic diagnostic for high speed projectiles," Rev. Sci. Instrum. Vol. 61, No. 8, p. 2102, 1990.

[20] M. J. Gouge, S. K. Combs, P. W. Fisher, and S. L. Milora, "Design considerations for single-stage and two-stage pneumatic pellet injectors," Rev. Sci. Instrum. Vol. 60, p. 570, 1989.

[21] S. L. Milora, S. K. Combs, M. J. Gouge, and R. W. Kincaid, "An algarithm for ertimating the performance of two-stage light gas guns," ORNLTM-1 1561, Oak Ridge National Laboratory, September 1990.

[22] G. Riva and A. Reggiori, "Modeling of pellet acceleration by twostage guns," Fusion Technol. Vol. 15, p. 143, 1989. 


\section{FIGURES}

\section{Fig. 1 Cryogenic hydrogen extruder (deuterium operation is depicted).}

Fig. 2 Tast configurations of the ORNL repeating pneumatic injector (RPI) teat facility with Frascati two-atuge gun.

Fig. 3 Schematic of the Frascati repenting two-stage light ges gun (RTSG).

Fig. 4 Schematic of ORNL/Frascati test facility.

Fig. 5 Experimental date for two test shots.

\section{DISCLAIMER}

This report was prepared as an account of work sponsored by an agency of the United States Government. Neither the United States Government nor any agency thereof, nor any of their employees, makes any warranty, express or implied, or assumes any legal liability or responsibility for the accuracy, completeness, or usefulness of any information, apparatus, product, or process disclosed, or represents that its use would not infringe privately owned rights. Referprocess disclosed, or represents that in to any specific commercial product, process, or service by trade name, trademark, manufacturer, or otherwise does not necessarily constitute or imply its endorsement, recommanufacturer, or otherwise the United States Government or any agency thereof. The views and opinions of authors expressed herein do not necessarily state or reflect those of the United States Government or any agency thereof. 


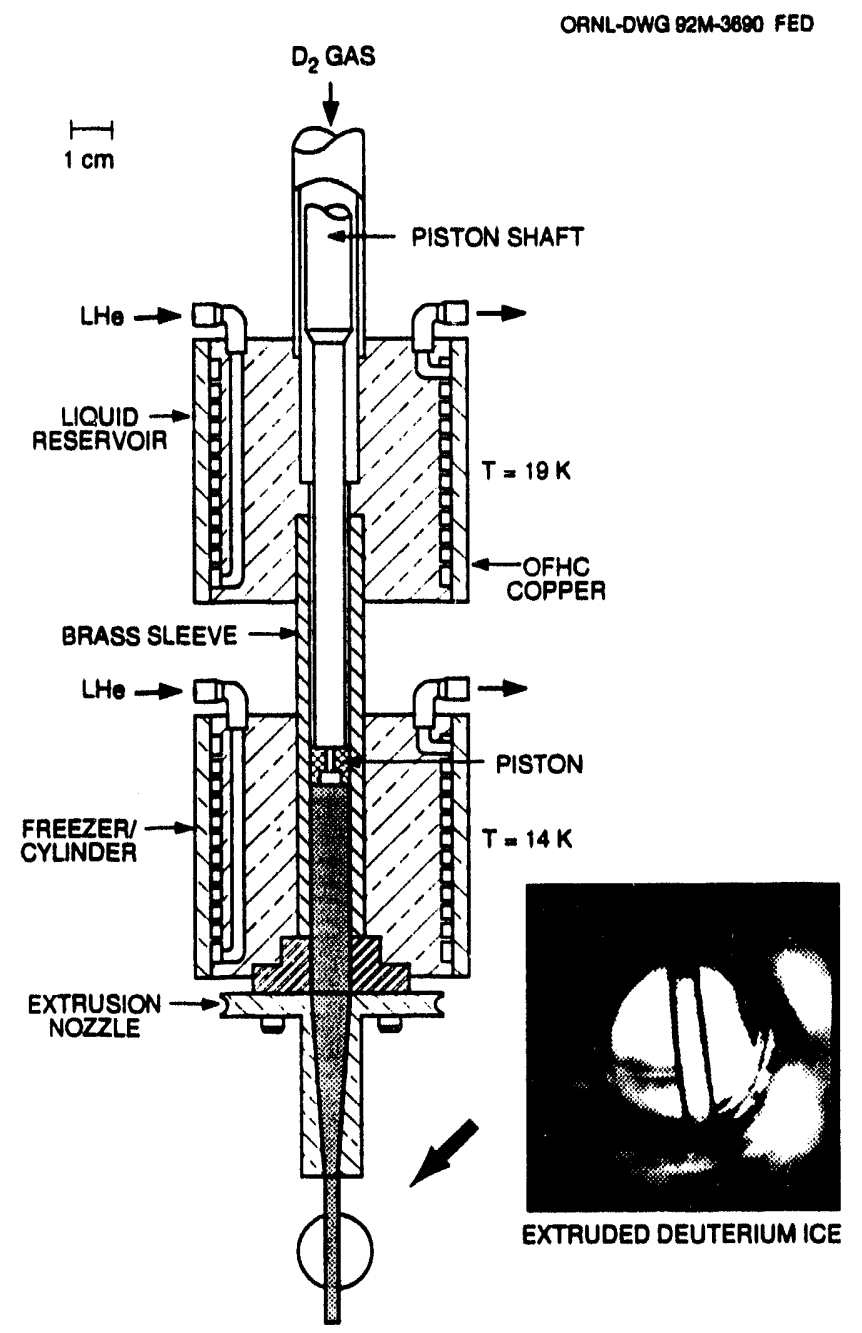


OANL-DWO 23M-2942 FED

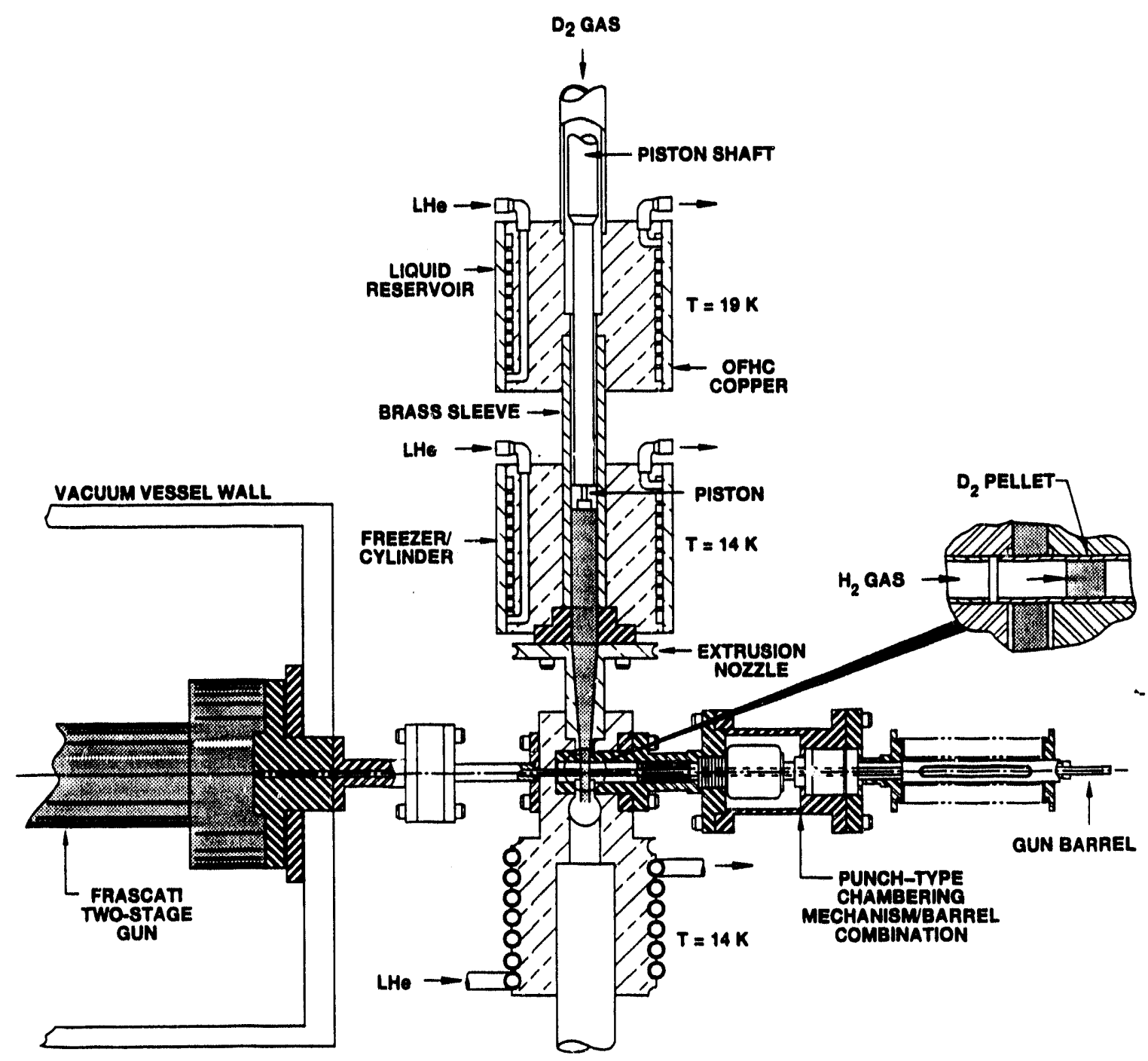


ORNL-DWG 93M-3812 FED

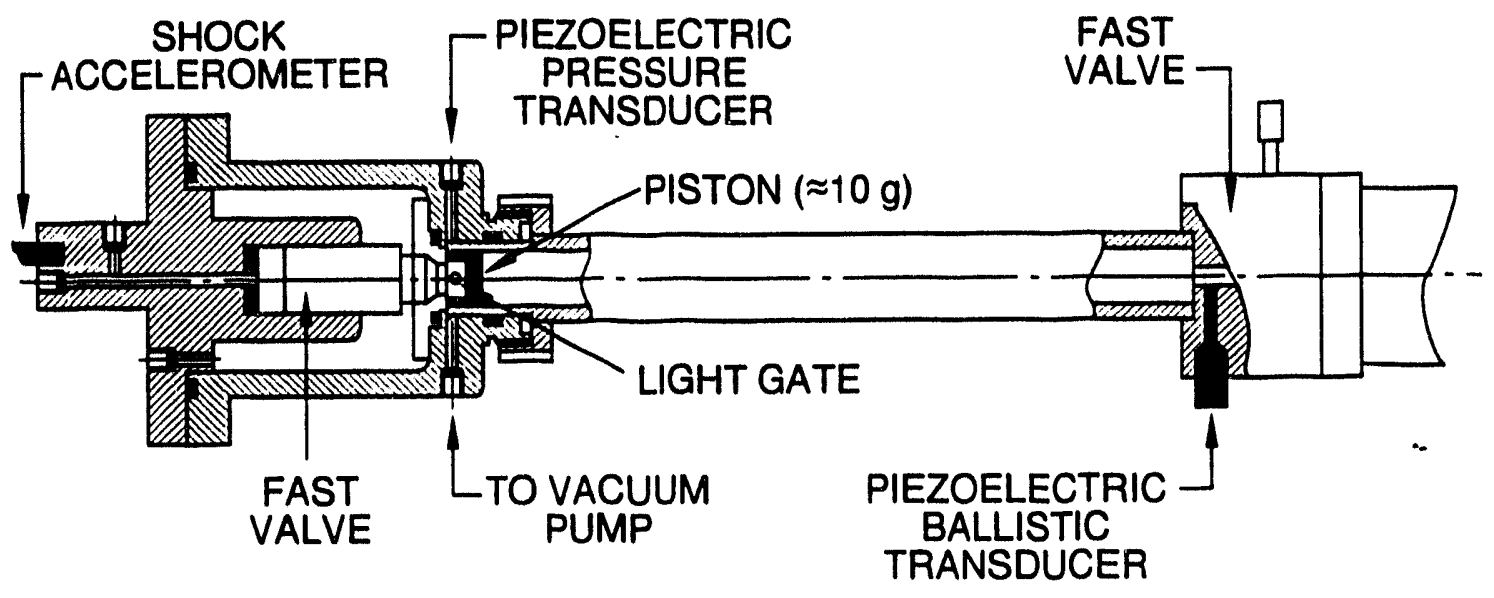




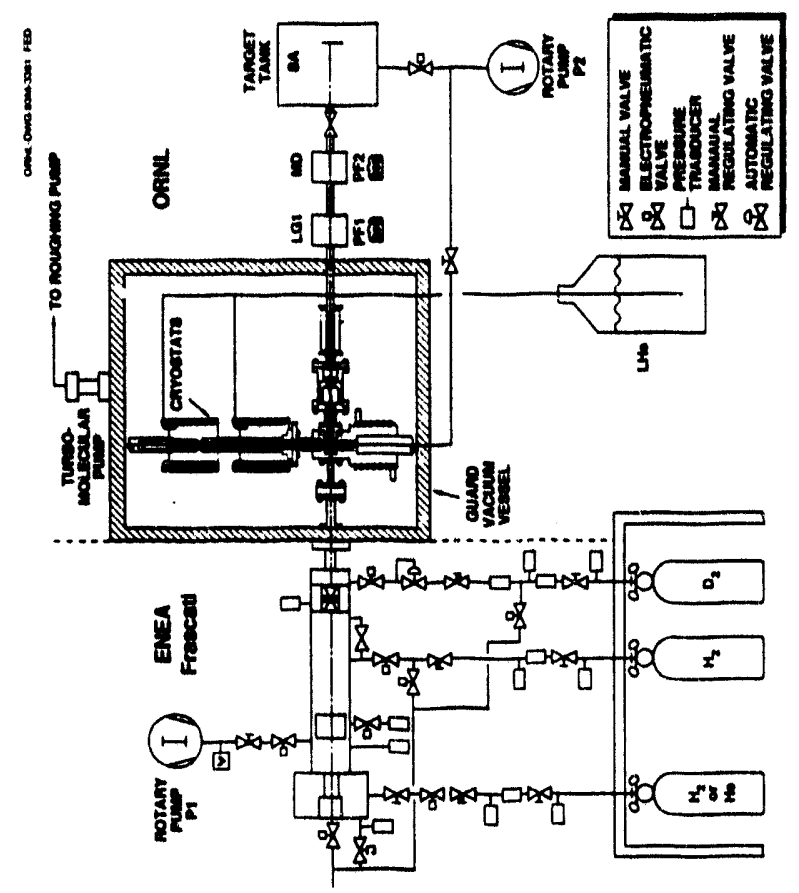




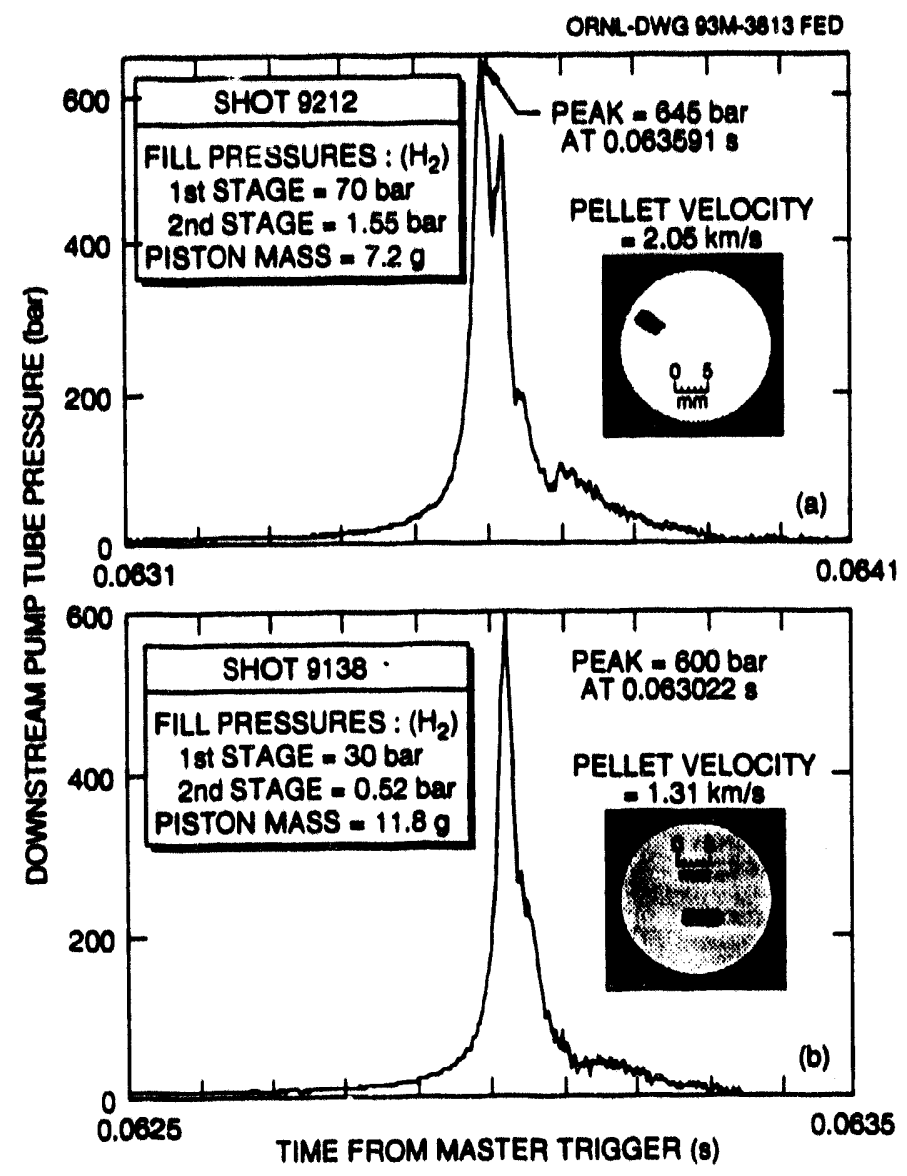



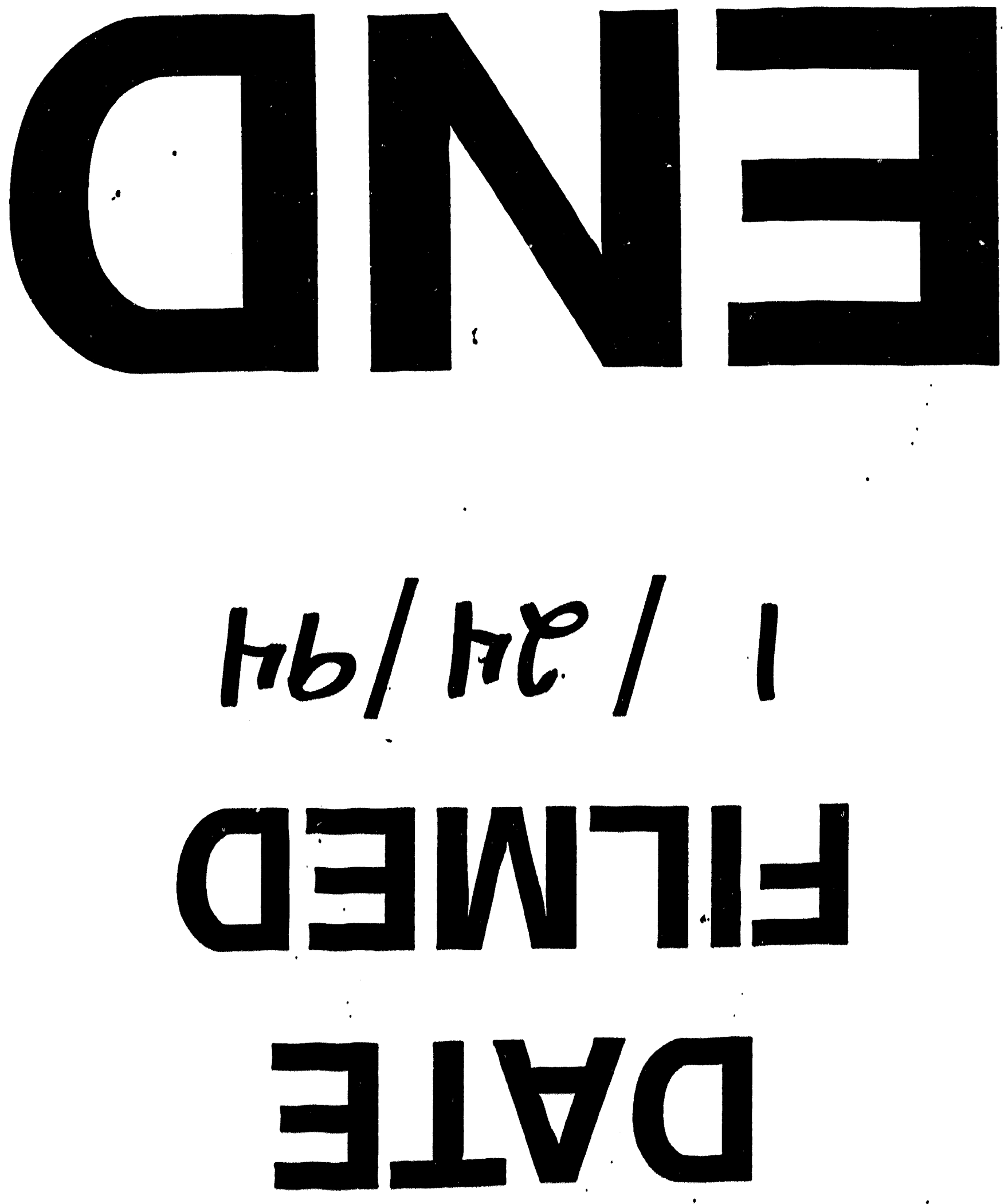
